\title{
Limb blood flow, cardiac output and quadriceps muscle bulk following spinal cord injury and the effect of training for the Odstock functional electrical stimulation standing system
}

\author{
P N Taylor BSc MSc MBES, ${ }^{1}$ D J Ewins BSc Phd MBES, ${ }^{1}$ B Fox SRP GradDipPhys \\ MCSP,${ }^{2}$ D Grundy FRCS, ${ }^{2}$ I D Swain BSc PhD CEng MIEE MBES ${ }^{1}$ \\ ${ }^{I}$ Department of Medical Physics and Biomedical Engineering, ${ }^{2}$ Duke of Cornwall Spinal \\ Treatment Centre, Odstock Hospital, Salisbury, Wiltshire, SP2 8BJ, England.
}

As part of the assessment of the Odstock functional electrical stimulation (FES) standing system for mid to low thoracic lesion spinal cord injured (SCI) subjects, cardiac output, thigh blood flow and quadriceps muscle thickness were measured before and following an electrical stimulation muscle retraining programme. The same parameters were also measured in a group of uninjured subjects and in SCI subjects. It was found that there was no difference in cardiac output between the groups. However thigh blood flow was found to be around $65 \%$ of normal values in the spinally injured group. This returned to normal values following the retraining programme. The quadriceps muscle wasted to approximately $50 \%$ of its original thickness in the first 3 weeks following spinal cord injury. The retraining programme increased the muscle thickness to near normal values.

Keywords: functional electrical stimulation; limb blood flow; cardiac output; muscle atrophy; muscle hypertrophy.

\section{Introduction}

Subjects with spinal cord injuries are encouraged to stand using passive systems such as the Oswestry standing frame or callipers to prevent contractures and reduce osteoporosis by loading the long bones. The Odstock functional electrical stimulation (FES) standing system attempts to provide a means of active, controlled, independent and safe standing for mid to low thoracic lesion paraplegics. ${ }^{1.2}$ The system consists of a two-channel computer controlled stimulator, knee angle sensors, and a wheelchair mounted balance aid. The quadriceps muscles are stimulated using surface electrodes, producing knee extension and locking the knees to allow weight bearing. The knee angle sensors consist of small servo potentiometers mounted on a lightweight, nonsupportive brace, attached to the leg by cuffs above and below the knee. The knee angle is fed back to the on-board microcomputer in the stimulator. Using an algorithm based on a proportional, integral and differential (PID) control technique, this information is used to determine the correct level of stimulation to maintain knee extension without causing hyperextension or knee flexion. Hence the system can compensate for muscle fatigue or changes in loading of the legs due to the subjects changing their posture. As the subjects have poor postural control, the wheelchair mounted balance aid is required to give security and support if required. ${ }^{3}$ Subjects can stand for up to 10 minutes, several times a day. The system can be used for functional tasks such as reaching a high shelf, standing at a bar or simply for therapeutic standing (Fig 1).

Subjects using electrical stimulation for retraining muscle have commonly reported that their legs feel warmer to the touch and their skin quality improves. It is postulated that this may be due to improved blood circulation. An increase in muscle bulk has also been reported and subjects have claimed an improved cosmetic appearance of the legs. This paper attempts to quantify these changes. 


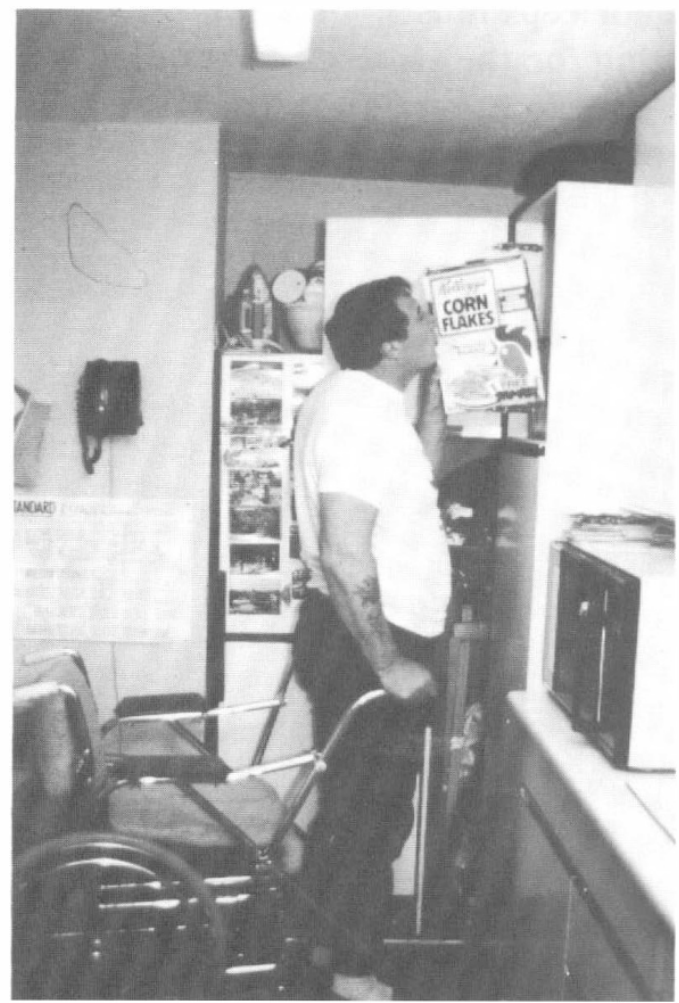

Figure 1 The Odstock FES standing system in use. The subject has a complete T12 lesion.

\section{FES training programme}

Before a subject can stand using FES, an exercise programme must be followed to strengthen the quadriceps muscles. ${ }^{4.5}$ The pulse width and pulse repetition frequency are fixed at 300 micro seconds and $20 \mathrm{~Hz}$ respectively and currents of up to $150 \mathrm{~mA}$ are used. The programme starts with simple isometric exercises and increases in duration, joint range and degree over a 3-month period.
Once the programme has been completed, the torque produced around the knee is measured using a purpose-built force measurement rig. With the subject supine and the knees supported in 30 degrees of flexion, the quadriceps are stimulated. The torque produced is calculated by measuring the upward force at the ankle and multiplying by the distance from the joint fulcrum, the knee joint. In order to stand, the subject must be able to produce $1 \mathrm{Nm}$ of torque per $\mathrm{kg}$ of body weight, per leg. If the subject fails to reach this target, a further period of training may be required.

\section{Method}

Cardiac output, thigh blood flow and quadriceps muscle depth were measured before commencing the muscle retraining programme and again once standing had been achieved (FES group). In order to put these measurements into context, cardiac output and thigh blood flow were measured in age-matched groups of uninjured subjects (control group) and also subjects with spinal cord injury (SCI group). No statistically significant difference in age could be found between these groups using Student's $t$ test. The course of quadriceps muscle atrophy was also followed on acute SCI subjects for the first month of their injury (acute group). On average this group was approximately 4 years younger than the other three groups (Table I).

Cardiac output and limb blood flow were measured by electrical impedance plethysmography using a Minnesota impedance cardiograph. ${ }^{6.7}$ The equipment passes a $100 \mathrm{kHz}, 4 \mathrm{~mA}$ signal between two electrodes at either end of a body segment. A

Table I Experimental groups

\begin{tabular}{lcrrrrr}
\hline Group & $\begin{array}{c}\text { Mean age } \\
\text { (Years and months) }\end{array}$ & SD & Males & Females & $\begin{array}{c}\text { Time post } \\
\text { injury } \\
\text { (Years and months) }\end{array}$ & SD \\
\hline Control & 27.8 & 12.9 & 16 & 3 & & \\
SCI & 28.3 & 10.7 & 18 & 2 & 6.7 & 7.6 \\
FES & 27.6 & 7.7 & 5 & 2 & 2.10 & 1.10 \\
Acute & 24.0 & 7.2 & 18 & 6 & & \\
\hline
\end{tabular}


second pair of electrodes, between the first set, records the rate of change of electrical impedance in a particular body segment due to the pulsatile nature of blood flow. From this the actual blood flow can be calculated. To measure cardiac output the subject lies supine and pairs of stainless steel electrodes, $4 \mathrm{~cm}$ apart on a webbing backing are placed around the neck and around the chest at the level of the sternal notch. Similarly, to measure thigh blood flow, pairs of electrodes are placed at the distal and proximal ends of the thigh. The subject is asked to hold their breath after a small inhalation. This prevents variation in thoracic impedance due to breathing while the measurement is made. Two sets of readings are taken. The first merely serves to check that the apparatus is set up correctly and to familiarise the subject with the procedure. The second, 20 minutes later, is taken to be the resting cardiac output and thigh blood flow. In this way, subject apprehension which may affect cardiac output, is minimised. Subjects had not performed any strenuous exercise, FES or otherwise, or consumed food or drink in the period one hour before the test.

Comparative studies have shown differences in absolute values of cardiac output between impedance plethysmography and other techniques. However a correlation coefficient of 0.91 was found by $\mathrm{Naggar}^{8}$ between impedance plethysmography and the direct Fick method. Van de Water et al ${ }^{9}$ compared the blood flow measurement taken by impedance plethysmography and by an electromagnetic flow meter in an artificial circuit and in the hind leg of a dog. The artificial circuit consisted of a liverwurst sausage, representing the limb, threaded through with a length of dog intestine, perfused with saline. A correlation coefficient of 0.94 was obtained in the artificial circuit and 0.91-0.96 in the in vivo measurement. Impedance plethysmography is therefore considered a suitable technique for comparative measurements.

Quadriceps muscle depth was measured using a linear array ultrasound scanner. With the subject supine and the legs in neutral position, the measurement was made $15 \mathrm{~cm}$ above the proximal border of the patella. From the resulting cross-section image, which was recorded on a video printer, the muscle depth and fat depth can be measured (Fig 2). The femur can be seen as a bright crescent, covered by the vastus intermedius and rectus femoris. Above the muscle is a layer of subcutaneous fat and skin. Measurements were taken using the scanner's electronic on-screen callipers from the highest part of the femur vertically to the skin surface. The depth of muscle and subcutaneous fat layers were later measured from the video printout. Kitecho stand-off gel, a layer of cushioning gel transparent to ultrasound, was used to prevent the weight of the scanner head from deforming the tissue being measured and to enable the surface of the skin to be imaged.

\section{Results}

Cardiac output and thigh blood flow

The mean cardiac output in the control group (Table II) was found to be $4780 \mathrm{ml}$ / $\min (\mathrm{s}=1360)$. This is a little lower than the accepted value of $5500 \mathrm{ml} / \mathrm{min}$, determined from invasive methods. There was no statistical difference in cardiac output between the control and SCI groups. Further, no statistically significant difference could be found in cardiac output between the FES

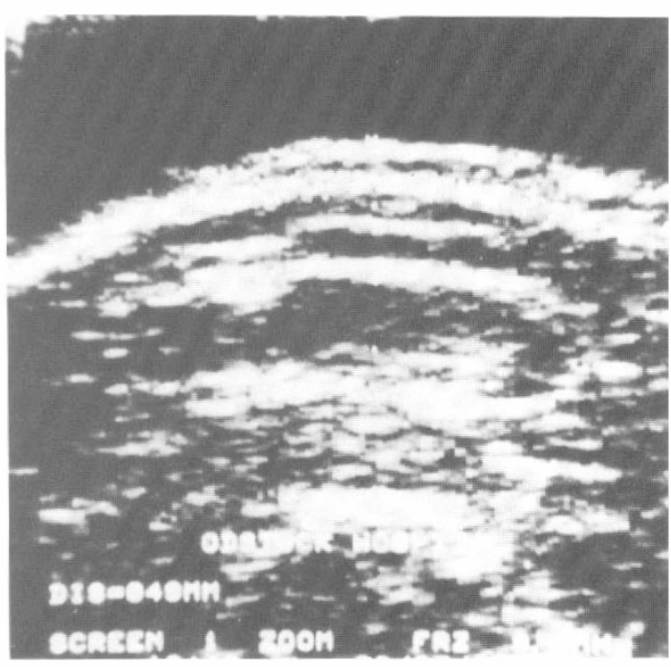

Figure 2 A linear array ultrasound cross-section scan of the thigh, $15 \mathrm{~cm}$ proximal to the patella. 
Table II Cardiac output and thigh blood flow in normals and SCI groups

\begin{tabular}{|c|c|c|c|c|c|}
\hline & \multicolumn{2}{|c|}{ Normals } & \multicolumn{2}{|c|}{ SCI } & \multirow[t]{2}{*}{ Student's $t$ tes } \\
\hline & Average & SD & Average & SD & \\
\hline $\begin{array}{l}\text { Cardiac output } \\
(\mathrm{ml} / \mathrm{min})\end{array}$ & 4780 & 1360 & 4550 & 1950 & $p>0.1$ \\
\hline $\begin{array}{l}\text { Thigh blood flow } \\
(\mathrm{ml} / \mathrm{min})\end{array}$ & 324 & 150 & 214 & 153 & $p<0.001$ \\
\hline $\begin{array}{l}\% \text { Cardiac output in } \\
\text { the thigh }\end{array}$ & 7.1 & 3.3 & 5.4 & 3.9 & $p<0.05$ \\
\hline
\end{tabular}

group and the control and SCI groups, either prior to, or following FES training (Table III). Although the mean cardiac output increased following FES training, this was not shown to be statistically significant using the paired $t$ test.

Measurement of thigh blood flow showed that on average the thigh blood flow of the SCI group was two thirds that of the control group. This result was shown to be statistically significant using Student's $t$ test $(p<0.001)$. The average thigh blood flow of the pretraining FES group was found to be comparable with the SCI group, using Student's $t$ test. FES training produced a statistically significant $(p<0.001)$ average increase of $115 \%$ causing the values for thigh blood flow to return values similar to those of the normals group with no statistically significant difference (Fig 3). To isolate the change in thigh blood flow from changes in cardiac output, the thigh blood flow was expressed as a percentage of cardiac output. Again the changes due to FES training were shown to be significant $(p<0.05)$.

\section{Quadriceps muscle depth}

Figure 4 shows the typical reduction in quadriceps muscle depth in the first month following SCI. In all subjects most of muscle atrophy occurred within the first 3 weeks of injury. Little change in the subcutaneous fat occurred in this period. As relatively few patients were admitted to the spinal injuries unit on the first day of injury, it was not possible to record the changes from day one of injury. However sufficient numbers were available to compare the fifth and twentieth day of injury. It was found that an average of $42 \%$ of muscle depth was lost within this period (Table IV). This was shown to be statistically significant using Student's $t$ test $(p<0.001)$. Measurement of subcutaneous fat showed no significant change over the same period. Six subjects were followed beyond the twentieth day and were found to have no further significant change in muscle or fat depth by the fortieth day. Four subjects were followed from the first day of injury and showed an average muscle reduction of $16 \%$ and a reduction of subcutaneous fat of $6.5 \%$ in the first 5 days.

Table III Cardiac output and thigh blood flow pre and post FES training.

\begin{tabular}{|c|c|c|c|c|c|c|c|}
\hline & \multicolumn{2}{|c|}{ Pre FES } & \multicolumn{2}{|c|}{ Post FES } & \multirow[t]{2}{*}{ Paired $t$} & \multicolumn{2}{|c|}{$\%$ Change } \\
\hline & Average & SD & Average & SD & & Average & SD \\
\hline $\begin{array}{l}\text { Cardiac output } \\
(\mathrm{ml} / \mathrm{min})\end{array}$ & 4360 & 2790 & 5230 & 1750 & $p>0.2$ & 56.6 & 95.6 \\
\hline $\begin{array}{l}\text { Thigh blood flow } \\
\text { (ml/min) }\end{array}$ & 167 & 70 & 328 & 151 & $p<0.001$ & 115 & 128 \\
\hline $\begin{array}{l}\% \text { Cardiac output } \\
\text { in thigh }\end{array}$ & 5.1 & 3.1 & 7.1 & 4.0 & $p<0.05$ & 5.3 & 74.3 \\
\hline
\end{tabular}



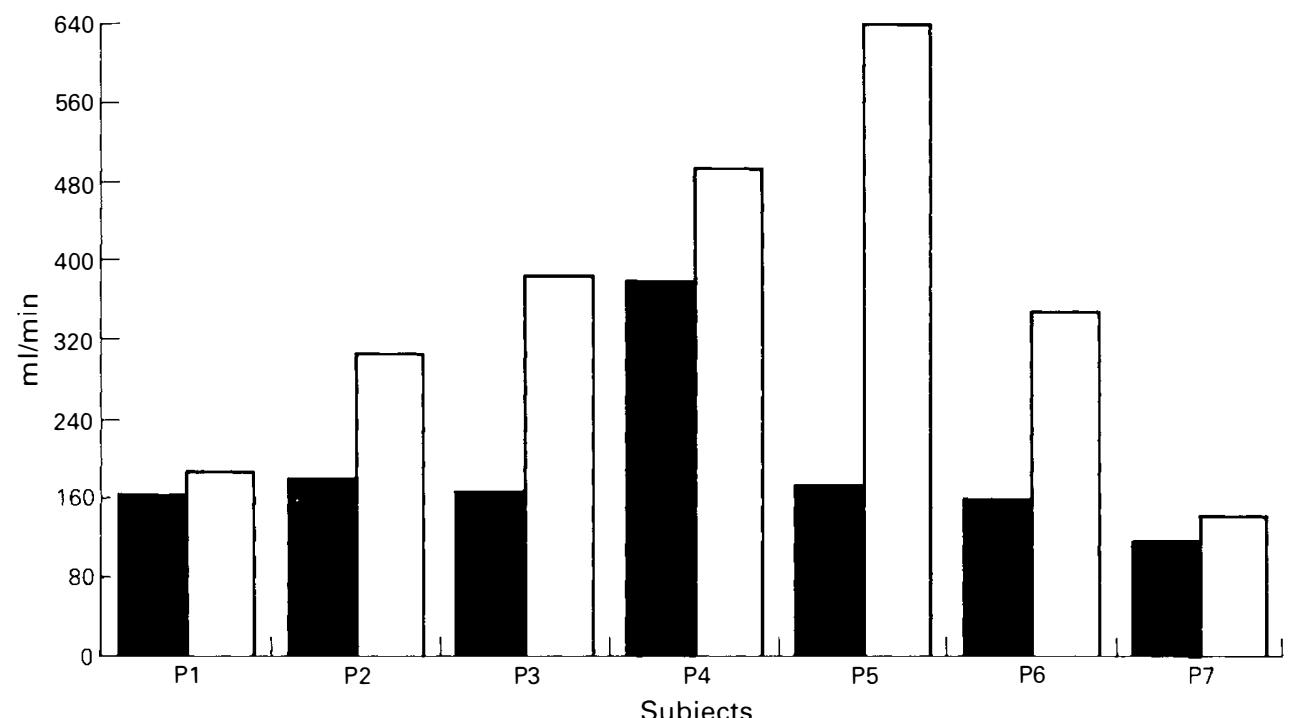

$\square$ pre training $\square$ R post training

Figure 3 Thigh blood flow before and after FES training, once standing had been achieved.

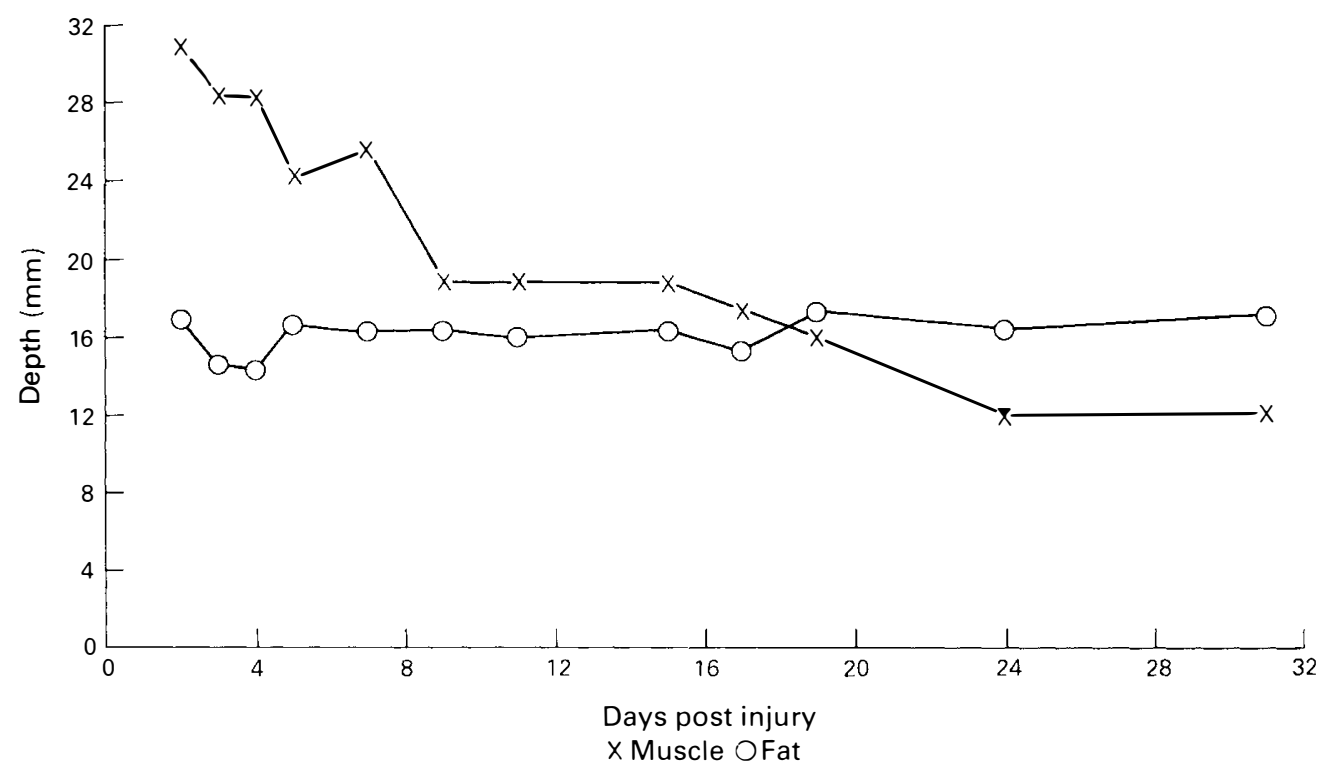

Figure 4 Quadriceps muscle and subcutaneous fat depth following spinal cord lesion. The subject, a 25 year old male, sustained a C5/6 lesion.

Although there is not enough data to permit statistical analysis, extrapolating between day 1 and day 20 gives an overall loss of muscle of around $50 \%$ and loss of subcutaneous fat of nearly $14 \%$.
FES training produced a significant change in muscle depth (Table V). Figure 5 shows the progress of a subject with a complete T4 lesion who achieved standing after exercising for 104 days. Overall, values 
Table IV Change in muscle and subcutaneous fat following SCI

\begin{tabular}{|c|c|c|c|c|c|c|}
\hline & \multicolumn{2}{|l|}{5 days post injury } & \multicolumn{2}{|l|}{20 days post injury } & \multirow{2}{*}{$\begin{array}{c}\text { Average } \\
\% \text { loss }\end{array}$} & \multirow[t]{2}{*}{ Paired $t$} \\
\hline & Average depth $(\mathrm{mm})$ & SD & Average depth $(\mathrm{mm})$ & SD & & \\
\hline Muscle & 21.9 & 4.5 & 12.8 & 3.0 & 41.8 & $p<0.001$ \\
\hline Subcutaneous fat & 16.5 & 4.3 & 15.6 & 5.2 & 7.8 & $p>0.2$ \\
\hline
\end{tabular}

Table $\mathbf{V}$ Changes in quadriceps muscle and subcutaneous fat after training with FES

\begin{tabular}{lccccccc} 
& \multicolumn{2}{c}{ Pre training } & & \multicolumn{2}{c}{ Post training } & \multicolumn{3}{c}{$\begin{array}{c}\text { Average } \\
\text { Paired } t\end{array}$} \\
\cline { 2 - 5 } & Average depth $(\mathrm{mm})$ & $\mathrm{SD}$ & $\begin{array}{c}\text { Average depth }(\mathrm{mm}) \\
\text { Ancrease }\end{array}$ & $\mathrm{SD}$ & & \\
\hline Muscle & 14.5 & 4.2 & 23.5 & 3.5 & 70.5 & $p<0.001$ \\
Subcutaneous fat & 15.9 & 4.4 & 17.1 & 3.6 & 15.3 & $p>0.2$ \\
\hline
\end{tabular}

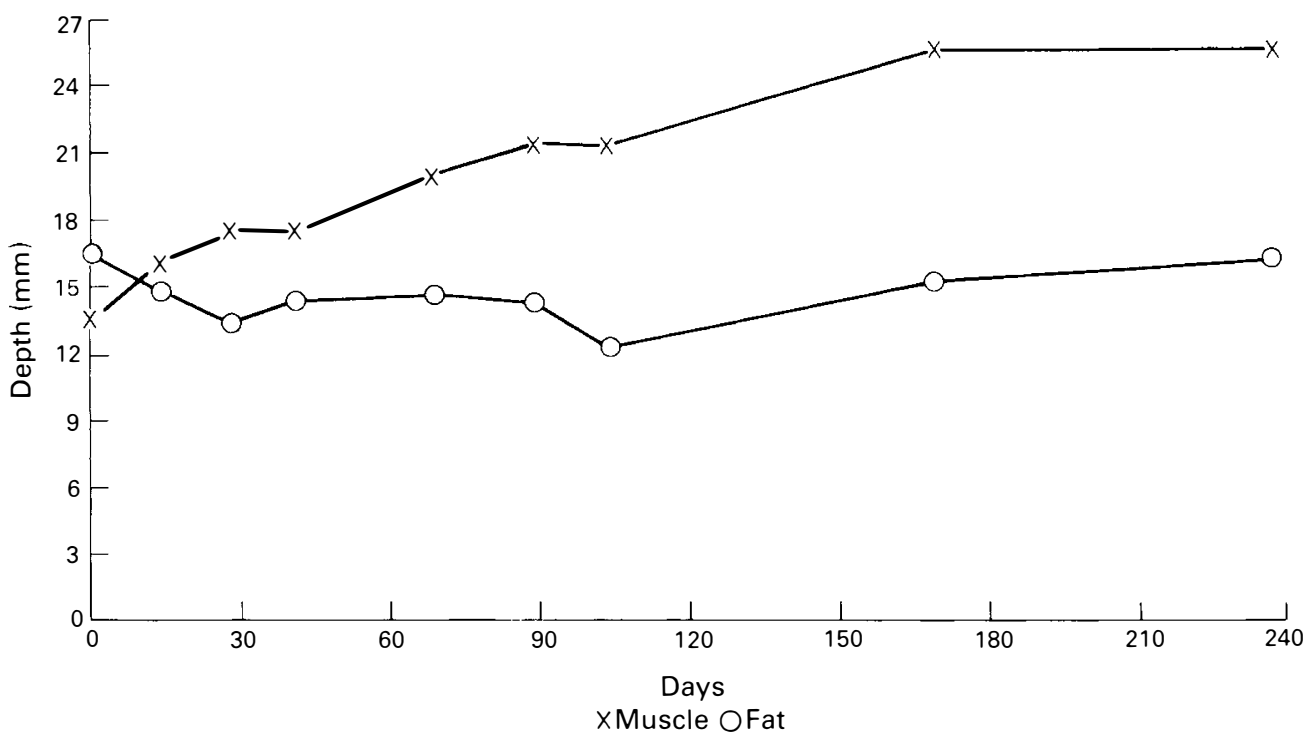

Figure 5 Quadriceps muscle and subcutaneous fat while following the FES training programme. The subject was a 27 year old male with a T4 lesion.

for muscle depth were increased to those typical of the acute group at day 5. This was shown to be statistically significant using Student's $t$ test $(p<0.001)$. Figure 6 shows the increase in muscle depth in the 7 candidates. Subject P7 showed no increase. However this subject started the programme with considerable spasticity and therefore had preserved a relatively large muscle bulk. No significant change in subcutaneous fat was recorded in any subject.

Comparing the percentage change in thigh blood flow with the percentage change in muscle depth, there was a statistically significant Spearman rank correlation coefficient of 0.623 . This suggests that the increase in thigh blood flow is related to the increase in muscle bulk. 


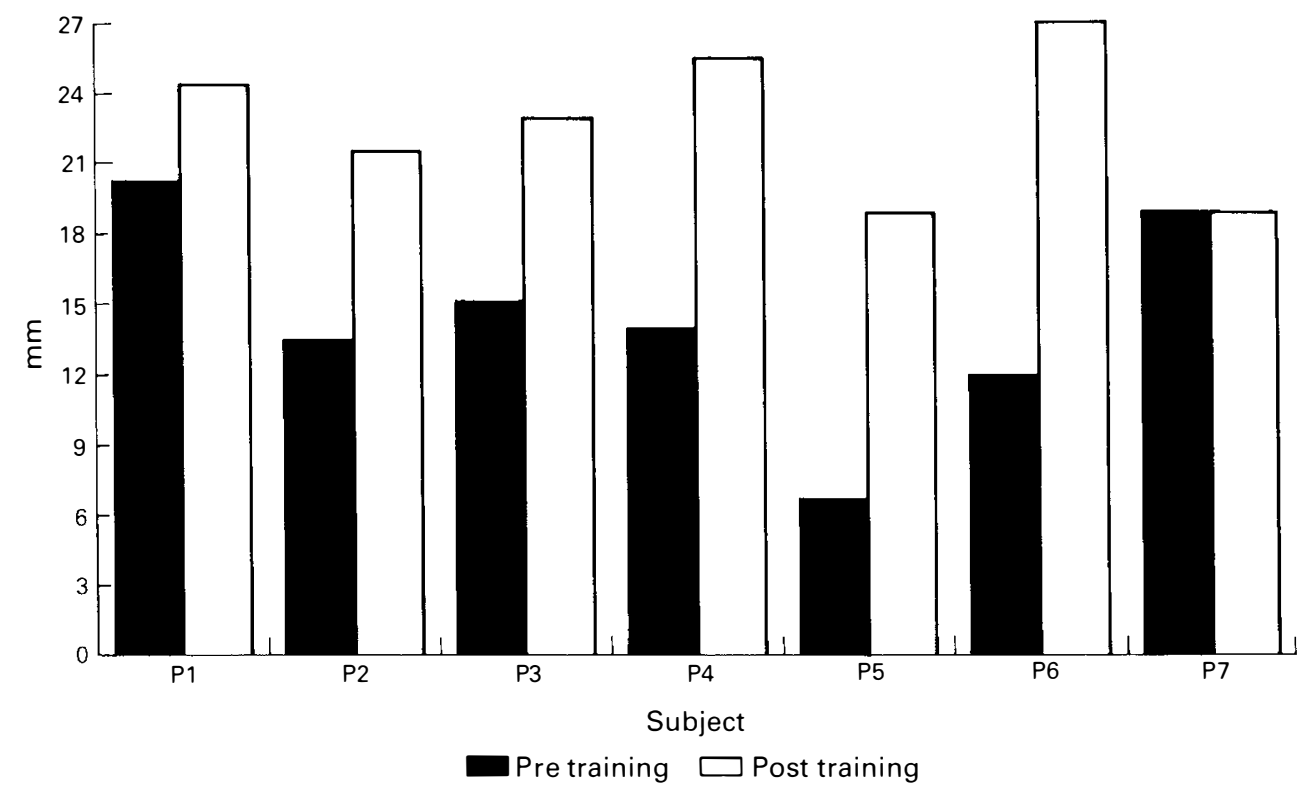

Figure 6 Quadriceps muscle depth before and after completing the FES training programme and once standing had been achieved.

\section{Conclusions}

There was no statistical difference in resting cardiac output between the control and SCI groups and no change following FES training. There is a one third reduction in resting thigh blood flow following spinal cord injury. Thigh blood flow returned to normal values following FES training. The percentage of the cardiac output also increased, suggesting that the effect is local and independent of cardiac output. Up to $50 \%$ of quadriceps muscle depth is lost in the first 3 weeks of injury and this returned to near normal levels by FES training. A correlation was found between percentage muscle depth increase and percentage thigh blood flow increase.

\section{Acknowledgements}

We wish to acknowledge the assistance of the staff and patients of the Duke of Cornwall Spinal Treatment Centre and also John Colvin who was involved in some of the original measurements. We would like to thank the Department of Health for funding this work (Agreement No 92/88).

\section{References}

1 Ewins DJ, Taylor PN, Crook SE, Lipcyznski RT, Swain ID (1988) Practical low cost stands/sit system for mid-thoracic paraplegics. J Biomed Eng 10(2): 184-188.

2 Ewins DJ, Taylor PN, Swain ID (1990) A functional closed-loop stand/sit system for mid-low thoracic paraplegics. In: D Popovic. D editor. Advances in External Control of Human Extremities 10. Nauka, Belgrade: 261-264.

3 Nash RSW, Davy MS, Orpwood R, Swain ID (1990) Development of a wheelchair mounted folding standing frame. J Biomed Eng 12(3): 189-192.

4 Taylor PN, Fox BA, Ewins DJ, Biss SJ, Swain ID (1989) Exercise procedure and treatment routine for preparation of paraplegics prior to standing using FES. In: F Clifford Rose, R Jones, G Vrbova, editors. Neuromuscular Stimulation: Basic Concepts and Clinical Implications. Demos Publications, New York: 245-251.

5 Barr FMD, Bayley JIL, Midleton FRI, Moffat B (1987) Functional electrical stimulation: practical experience in the clinical setting. In: D Popovic, editor. Advances In External Control Of Human Extremities 9. Taujug, Belgrade: 181-192. 
6 Kubicek WG, Karnegis JN, Patterson RP, Witsoe DA, Mattson RH (1966) Development and evaluation of an impedance cardiac output system. Aerospace Med 37(12): 1208-1212.

7 Porter JM, Swain ID, Shakespeare PG (1985) Measurement of limb blood flow by electrical impedance plethysmography. Ann R Coll Surg Engl 67: 169-172.

8 Naggar CZ, Dobnik DB, Flessas AP, Kripke BJ, Ryan TJ (1975) Accuracy of stroke index as determined by the tranthoracic electrical impedance method. Anaesthesiology 42(2): 46-56.

9 Van de Water JM, Dmochowski JR, Dove GB. Couch NP (1979) Evaluation of an impedance flow meter in arterial surgery. Surgery 3: 132-137. 